\title{
Antibiotics for bronchiectasis exacerbations in children: rationale and study protocol for a randomised placebo-controlled trial
}

Anne B Chang ${ }^{1,2,3^{*}}$, Keith Grimwood ${ }^{3,4}$, Colin F Robertson ${ }^{5}$, Andrew C Wilson ${ }^{6}$, Peter P van Asperen ${ }^{7}$, Kerry-Ann F O'Grady ${ }^{3}$, Theo P Sloots ${ }^{3,4}$, Paul J Torzillo ${ }^{8}$, Emily J Bailey ${ }^{1,2,3}$, Gabrielle B McCallum ${ }^{1}$, Ian B Masters ${ }^{2,3}$, Catherine A Byrnes ${ }^{9}$, Mark D Chatfield ${ }^{10}$, Helen M Buntain ${ }^{2,3}$, lan M Mackay ${ }^{3,4}$ and Peter S Morris ${ }^{1,11}$

\begin{abstract}
Background: Despite bronchiectasis being increasingly recognised as an important cause of chronic respiratory morbidity in both indigenous and non-indigenous settings globally, high quality evidence to inform management is scarce. It is assumed that antibiotics are efficacious for all bronchiectasis exacerbations, but not all practitioners agree. Inadequately treated exacerbations may risk lung function deterioration. Our study tests the hypothesis that both oral azithromycin and amoxicillin-clavulanic acid are superior to placebo at improving resolution rates of respiratory exacerbations by day 14 in children with bronchiectasis unrelated to cystic fibrosis.
\end{abstract}

Methods: We are conducting a bronchiectasis exacerbation study (BEST), which is a multicentre, randomised, doubleblind, double-dummy, placebo-controlled, parallel group trial, in five centres (Brisbane, Perth, Darwin, Melbourne, Auckland). In the component of BEST presented here, 189 children fulfilling inclusion criteria are randomised (allocation-concealed) to receive amoxicillin-clavulanic acid (22.5 mg/kg twice daily) with placebo-azithromycin; azithromycin (5 mg/kg daily) with placebo-amoxicillin-clavulanic acid; or placebo-azithromycin with placeboamoxicillin-clavulanic acid for 14 days. Clinical data and a paediatric cough-specific quality of life score are obtained at baseline, at the start and resolution of exacerbations, and at day 14. In most children, blood and deep nasal swabs are also collected at the same time points. The primary outcome is the proportion of children whose exacerbations have resolved at day 14 . The main secondary outcome is the paediatric cough-specific quality of life score. Other outcomes are time to next exacerbation; requirement for hospitalisation; duration of exacerbation; and spirometry data. Descriptive viral and bacteriological data from nasal samples and blood markers will also be reported.

Discussion: Effective, evidence-based management of exacerbations in people with bronchiectasis is clinically important. Yet, there are few randomised controlled trials (RCTs) in the neglected area of non-cystic fibrosis bronchiectasis. Indeed, no published RCTs addressing the treatment of bronchiectasis exacerbations in children exist. Our multicentre, double-blind RCT is designed to determine if azithromycin and amoxicillin-clavulanic acid, compared with placebo, improve symptom resolution on day 14 in children with acute respiratory exacerbations. Our planned assessment of the predictors of antibiotic response, the role of antibiotic-resistant respiratory pathogens, and whether early treatment with antibiotics affects duration and time to the next exacerbation, are also all novel.

Trial registration: Australia and New Zealand Clinical Trials Register (ANZCTR) number ACTRN12612000011886.

Keywords: Amoxicillin-clavulanic acid, Azithromycin, Bronchiectasis, Placebo, Pulmonary exacerbations, Randomised controlled trial

\footnotetext{
* Correspondence: annechang@ausdoctors.net

${ }^{1}$ Child Health Division, Menzies School of Health Research, Charles Darwin

University, Darwin, NT, Australia

${ }^{2}$ Queensland Children's Respiratory Centre, Royal Children's Hospital,

Brisbane, QLD, Australia

Full list of author information is available at the end of the article
}

\section{Biomed Central}

(c) 2012 Chang et al.; licensee BioMed Central Ltd. This is an Open Access article distributed under the terms of the Creative Commons Attribution License (http://creativecommons.org/licenses/by/2.0), which permits unrestricted use, distribution, and reproduction in any medium, provided the original work is properly cited. 


\section{Background}

Compared to the early 20th century, the prevalence of bronchiectasis has fallen substantially. Although regarded as an 'orphan disease' in affluent countries, reports of prevalence of bronchiectasis are increasing $[1,2]$. Bronchiectasis remains a major contributor to chronic respiratory morbidity [2,3] and mortality [1,4] in both Indigenous [5] and non-Indigenous populations [6]. In our recently completed multicentre study of children newly referred for chronic cough and managed in accordance to a standardised protocol [7], 31 (9\%) of the 346 children had bronchiectasis proven on radiology [8]. In the Northern Territory in Australia, the incidence of bronchiectasis in the first year of life is 118 in 100,000 [9]. The estimated prevalence of bronchiectasis is 1,470 per 100,000 in Central Australian Indigenous children aged below 15 years [10] and 1,600 per 100,000 in Alaskan Native children [11]. In the United States, reported prevalence in adults range from 4.2 to 271.8 per 100,000 [6]. However, any reported prevalence is likely to be an underestimate as many cases are misdiagnosed or coexist with other diseases like asthma [12-14] and chronic obstructive pulmonary disease (COPD) [15]. Even without accounting for these unrecognised cases, globally there are far more patients with bronchiectasis than cystic fibrosis (CF), which has a prevalence of 7.4 to 7.9 per 100,000 in the European Union and the United States [14].

Effective clinical management reduces both short- and long-term morbidity (and likely mortality) associated with bronchiectasis [16-18]. There is increasing evidence that intensive treatment of children who either have bronchiectasis or are at risk of developing severe bronchiectasis prevents poor lung function in adulthood [17-20]. Cohort data have shown that approximately $80 \%$ of newly diagnosed adults (non-smokers) with bronchiectasis reported symptoms dating back to childhood and that the duration of chronic cough (the most common symptom of bronchiectasis [21]) was related $(r=-0.51, P<0.001)$ to lung function at diagnosis [22]. Arguably, appropriate overall management and treatment of exacerbations (leading to reduction of persistent symptoms) potentially prevents or reduces deterioration of chronic respiratory disease [23].

Determinants of accelerated lung function decline in adults with bronchiectasis are the frequency of hospitalised exacerbations, increased systemic inflammatory markers and Pseudomonas aeruginosa infection [24]. Amongst other factors, increased mortality risk is associated with the degree of lung function impairment [25]. No prospective data exist in children. Our study and a London-based retrospective study found that, with appropriate treatment in specialised centres, lung function improves and can be maintained $[18,20]$. However, those with poor lung function at diagnosis, although substantially improved, were likely to still have poor lung function five years later [20].
We also found that the only significant predictor of a decline in forced expiratory volume in one second $\left(\mathrm{FEV}_{1}\right)$ was frequency of hospitalised exacerbations [20]. Forced expiratory volume in one second $\left(\mathrm{FEV}_{1}\right) \%$ predicted decreased by $1.95 \%$ with each previous hospitalised exacerbation [20]. As airway injury in children is superimposed upon the physiological changes involving lung growth and development [26,27], improvement in childhood bronchiectasis may impact favourably upon future adult lung function. Early and effective management of bronchiectasis exacerbations in children may lead to reduced hospitalisations, better quality of life (QOL) and improved future adult lung function.

Antibiotics are one of the key interventions used to treat acute respiratory exacerbations of bronchiectasis $[21,28]$. However, it is biologically plausible that antibiotics are not useful for treating some respiratory exacerbations triggered by viral infections. Our retrospective study found that $34 \%$ of exacerbations were preceded by a viral-like illness [29]. While most respiratory physicians will treat exacerbations intensively (with antibiotics and airway clearance), other doctors do not. Those choosing not to use antibiotics routinely argue that most episodes of exacerbations and cough are caused by viral infections and hence do not require antibiotic therapy. This may be appropriate but viral-bacterial interactions in the airways risk prolonged endobronchial bacterial infection that, with the associated inflammatory cascade, may cause further lung injury $[23,30]$. Better evidence to guide the management of exacerbations in people with bronchiectasis is needed.

\section{Aims of the study}

There are two components of BEST; here we present the study protocol of the first phase (BEST-1). The second phase of BEST (BEST-2) will address the question "Is daily azithromycin non-inferior (within $20 \%$ margin) to amoxicillin-clavulanic acid in achieving resolution of exacerbations on day 21?" The protocol for BEST-2 will be the subject of a later paper.

This first phase of our proposed national multicentre double-blind double-dummy randomised controlled trial (RCT) is designed to answer our primary questions, as follows. Amongst children with non-CF bronchiectasis, does azithromycin improve the resolution of respiratory exacerbations by day 14 compared with placebo, and does amoxicillin-clavulanic acid improve the resolution of respiratory exacerbations by day 14 compared with placebo?

Our secondary aims are to:

1. determine the effect of azithromycin or amoxicillinclavulanic acid on the QOL, systemic inflammation, time to next respiratory exacerbation, and duration of exacerbations; 
2. explore factors that predict response to antibiotics, including respiratory pathogens (viruses, bacteria, macrolide-resistant bacteria) present in respiratory secretions and blood markers; and

3. describe the point prevalence and diversity of respiratory viruses, Mycoplasma pneumoniae and Chlamydia species during exacerbations using sensitive molecular detection techniques.

Our study tests the primary hypothesis that both oral azithromycin and amoxicillin-clavulanic acid are superior to placebo in improving the resolution rate of respiratory exacerbations by day 14 in children with non-CF bronchiectasis.

\section{Methods/Design \\ Study design}

We are conducting a multicentre, parallel group, double-blind placebo RCT (with concealed allocation) to assess the impact of treatment with antibiotics (azithromycin or amoxicillinclavulanic acid) in children with an exacerbation of bronchiectasis. Our study plan is summarised in Figure 1.

\section{Eligibility}

The inclusion criteria are age below 18 years at time of study enrolment; diagnosed with bronchiectasis by a respiratory physician following high resolution computed tomography in the five years immediately prior to study entry or, if diagnosed earlier, have been followed regularly by a respiratory physician for treatment of bronchiectasis; and has experienced two or more respiratory exacerbations in the 18 months prior to study entry.

Exclusion criteria are current severe exacerbation of bronchiectasis (dyspnoea, hypoxia or hospitalisation), recent (in last 8 weeks) in the entry; CF; liver dysfunction;

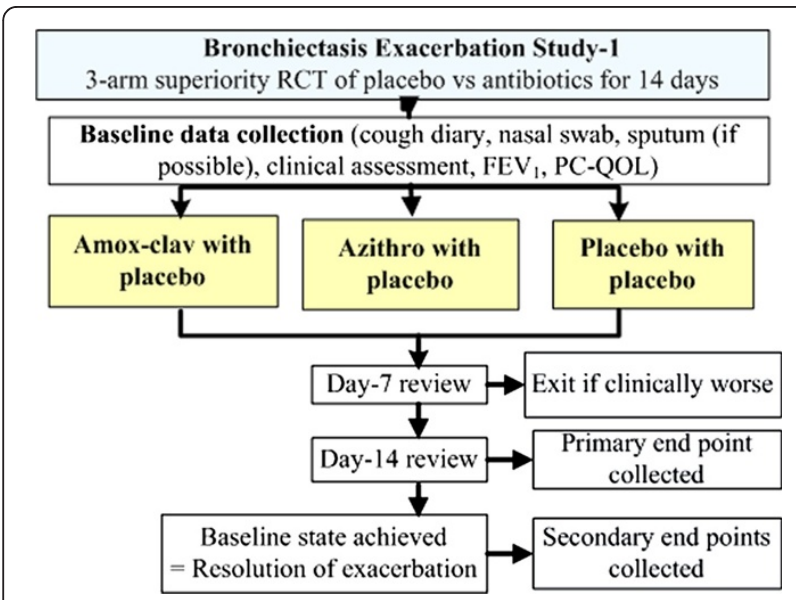

Figure 1 Overall schematic study design. Amox-clav: amoxicillinclavulanic acid; azithro: azithromycin. allergy or sensitivity to penicillin or macrolides; current or recent lower airway infection by a member of the Pseudomonas genus group of Gram-negative bacteria (in the four months prior to study enrolment); has received antibiotics belonging to the macrolide or penicillin class of antibiotics within three weeks immediately prior to study entry; or is currently receiving oncological treatment.

\section{Recruitment}

Eligible children will be identified from clinics in our centres (Brisbane, Perth, Darwin and Melbourne in Australia and Auckland in New Zealand). Parents will be approached and informed consent obtained. Baseline pre-exacerbation data will be collected (Figure 1), parents contacted monthly and children reviewed every three months. Parents will be educated specifically on symptoms of exacerbations and asked to contact the research nurse at the onset of an exacerbation.

\section{Intervention and follow-up}

A double-dummy design is planned. If eligibility is fulfilled and after informed consent has been obtained, the child is randomised to one of three arms. At the start of the exacerbation, the child will receive amoxicillinclavulanic acid with placebo-azithromycin, azithromycin with placebo-amoxicillin-clavulanic acid or placeboazithromycin with placebo-amoxicillin-clavulanic acid. Amoxicillin-clavulanic acid dose is $22.5 \mathrm{mg} / \mathrm{kg} / \mathrm{dose}$ (up to $40 \mathrm{~kg}$ ) twice a day (max $900 \mathrm{mg} /$ dose). Azithromycin dose is $5 \mathrm{mg} / \mathrm{kg} /$ day, max of $200 \mathrm{mg}$ daily. Equivalent volumes in placebo will be given in all arms. All treatments will continue for 14 days.

An exacerbation is defined as an increase in sputum volume or purulence, or three or more days of change in cough ( $>20 \%$ increase in cough score [31] or type (dry to wet) [32]). We validated this definition in our prospective study and found that the kappa values (between clinicians) of these symptoms and signs were excellent $(>0.75)$ [33]. Daily diaries will also be collected during exacerbations until the scores for two or more days reflect the child's 'baseline' state, which for each child will be established at enrolment, prior to any exacerbations. This assessment consists of a combination of symptoms (daily cough (yes/no), cough quality (wet/dry/none) and cough score [31] averaged over two consecutive days) and signs (sputum colour (if any present) using a colour chart card (BronkoTest Ltd, London, UK), crackles on chest auscultation). Children will be reviewed on days 7 and 14 and at resolution of the exacerbation. The exacerbation is considered 'resolved' when symptoms and signs are the same as 'baseline' state. Post exacerbation, the children will be followed-up and clinically evaluated every three months for 18 months or until their next 
exacerbation. 'Time to next exacerbation' will be determined by the number of days from 'resolution of current exacerbation' to beginning of the next exacerbation.

\section{Randomisation, allocation and blinding}

Upon enrolment, the child is assigned to the next unique number on the appropriate stratified list. The allocation will be performed by the trial pharmacist at the Royal Children's Hospital in Brisbane. Randomisation is stratified by site (Brisbane, Perth, Darwin, Melbourne, Auckland), age ( $\leq 5$ or $>5$ years) and underlying aetiology (idiopathic/post-pneumonia or all other causes). The randomisation sequence was computer generated and used permuted blocks. The allocation sequence is concealed at all times throughout the study. The computer generated allocation sequence was prepared by a statistician external to the study team.

The placebo medications, specifically manufactured by the Institute of Drug Technology Australia Limited (Melbourne, Victoria), have a similar taste and colour to their respective antibiotics. Both active medications (amoxicillin-clavulanic acid and azithromycin) are repackaged by the Institute of Drug Technology. Thus both the amoxicillin-clavulanic acid and azithromycin and their respective placebos are in identical opaque bottles. For both types of trial medications, equal volumes of water are added using a syringe and needle by punching the seal. Adherence will be assessed by parent report and return of empty bottles.

\section{Data collection}

All data will be recorded on standardised forms. On enrolment, demographic information (age, gender, ethnicity, household size, and so on), birth history, breast feeding history, prior illness and in utero and household smoke exposure will be recorded, and a physical examination will be performed by a study physician. The primary and secondary outcome measures (see below) are collected at the time points specified above. Serious and non-serious adverse effects (nausea, vomiting, diarrhoea, rash) will also be documented and monitored. Safety exit points are discussed in End points below.

\section{Specimen collection}

At enrolment (baseline), all children will have a deep nasal swab (NS) specimen collected. In a subset, additional specimens will be collected at baseline and during exacerbations depending on feasibility (some children are unable to attend the study centre at the onset of the exacerbation) and willingness of parents to allow additional venipuncture. These specimens are:

- A deep NS specimen for respiratory viruses, respiratory bacterial pathogens (with antibiotic susceptibility testing) and other potentially important respiratory pathogens (M. pneumoniae, Chlamydia spp) at baseline and at the beginning and resolution of an exacerbation. The technique used is identical to previous studies [34-36] where the specimens were described as nasopharyngeal swabs. The NSs are handled as per our research laboratory protocol (see below).

- Bloods at baseline and at the beginning and end of each exacerbation for C-reactive protein (CRP), neutrophilic marker of inflammation (IL-6) [37], serum amyloid A (SAA) [33,38] and markers of viral infection (interferon gamma-inducible protein 10 (IP-10) and IL-10).

- Sputum at baseline and at the beginning and end of each exacerbation (when possible) for lower airway microbiology and antibiotic sensitivity.

\section{Further description of scores and laboratory methods Cough score}

The verbal categorical descriptive score is a validated daily diary score of cough rated on a six-point scale $(0=$ no cough to $5=$ severe cough and cannot perform activities) with increasing scores reflecting greater interference with usual activities. This rating was validated against an objective cough meter measure [31] and changes in cough scores have been shown to reflect changes in objective cough counts [39].

\section{Parent Chronic Cough Quality of Life score}

The Parent Chronic Cough Quality of Life (PC-QOL) is a 27-item questionnaire designed to assess the level of frequency of feelings (15 items) and worry (12 items) related to their child's cough. It uses a seven-point Likert-type scale with higher scores reflecting less frequency and fewer worry concerns (that is, greater QOL) $[40,41]$. The minimal important difference is 0.62 determined by the distribution method and 0.9 determined by the anchor method [42].

\section{Bacteriology of nasal swabs}

Oropharyngeal sampling under estimates Streptococcus pneumoniae carriage by approximately $50 \%$ when compared with NS [43]. Thus, NS are the preferred method when evaluating the presence of antibiotic-resistant bacteria. Culturing, identifying and, when appropriate, serotyping common respiratory bacteria are established techniques at our research laboratory $[36,44]$. Swabs are stored in skim milk tryptone glucose glycerol broth medium at $-80^{\circ} \mathrm{C}$ before being batch processed for typical respiratory bacterial pathogens, notably Haemophilus influenzae (including strains of non-typeable H. influenzae), Moraxella catarrhalis and S. pneumoniae. Batches of swabs are thawed and $10-\mu \mathrm{L}$ aliquots cultured overnight 
on selective media at $37^{\circ} \mathrm{C}$ in $5 \%$ carbon dioxide. Growth of S. pneumoniae, $H$. influenzae and $M$. catarrhalis is recorded and confirmed by standard techniques [36,45]. Four isolates each of S. pneumoniae and $H$. influenzae and two isolates of $M$. catarrhalis per positive swab are tested for antimicrobial resistance and stored $[36,45]$. S. pneumoniae isolates are serotyped using the Quellung method (antisera from Statens Serum Institute, Copenhagen,Denmark).

In addition to routine susceptibility testing using the calibrated dichotomous susceptibility disc diffusion method, azithromycin minimum inhibitory concentration (MIC) will be determined by Etests (AB Biodisk, Solna, Sweden) if the azithromycin disc annulus is $<6 \mathrm{~mm}$. For $S$. pneumoniae, the penicillin MIC is determined for penicillin non-susceptible isolates (oxacillin and/or penicillin disc annulus $<6 \mathrm{~mm}$ ) and for $H$. influenzae, the ampicillin MIC is determined for isolates if the ampicillin disc annulus is $<6 \mathrm{~mm}$. Interpretive criteria (Clinical and Laboratory Standards Institute breakpoints) used for $S$. pneumoniae are penicillin non-susceptible MIC $>0.12 \mu \mathrm{g} / \mathrm{mL}$, azithromycin resistance $\mathrm{MIC} \geq 2 \mu \mathrm{g} / \mathrm{mL}$; and for $H$. influenzae, ampicillin resistance $\mathrm{MIC} \geq 4 \mu \mathrm{g} / \mathrm{mL}$, azithromycin resistance $\mathrm{MIC}>4 \mu \mathrm{g} / \mathrm{mL}$. A nitrocephin-based test will identify beta-lactamase activity in $H$. influenzae and $M$. catarrhalis isolates.

\section{Assessment for viruses and atypical bacteria}

We will use our previous methods $[46,47]$. Nucleic acids will be extracted from the media using the High Pure Viral Nucleic Acid kit (Roche Diagnostics, Sydney, New South Wales, Australia), according to the manufacturer's instructions. Real-time polymerase chain reaction assays will be used to detect respiratory syncytial viruses (A and $B)$, adenoviruses, influenza viruses (A and B), parainfluenza, human metapneumovirus, human coronaviruses (OC43, HK1, 229E, NL63), enteroviruses, rhinoviruses (and subtypes [48]) and the more recently described human viruses (human bocavirus 1, parechoviruses, human polyomaviruses $\mathrm{K} 1$ and $\mathrm{WU})$ and $M$. pneumoniae and Chlamydia species [49].

\section{Blood markers}

Serum CRP (threshold $5 \mathrm{mg} / \mathrm{L}$ ) are standard tests that will be analysed locally (diagnostic laboratory of each participating centre). SAA, IL-6 (threshold $<3 \mathrm{pg} / \mathrm{mL}$ ), IL-10 (threshold $<0.5 \mathrm{pg} / \mathrm{mL}$ ) and IP-10 (threshold $2.8 \mathrm{pg} / \mathrm{mL}$ ) will be performed using ELISA commercial kits (R\&D Systems, Minneapolis, MN, USA) at our research laboratory.

\section{Spirometry}

Spirometry (in children aged $\geq 5$ years) will be performed using American Thoracic Society criteria and the $\mathrm{FEV}_{1} \%$ predicted recorded. We elected not to use oscillatory measures as we found no difference in airway resistance between steady and exacerbation states [33]. Thus we will use conventional spirometry although we do not expect to detect significant differences.

\section{End points}

Participation is complete when the child's clinical state returns to baseline and the 'time to next exacerbation' has been obtained. Other exit points are if the child is clinically worse prior to day 14 or intolerance to the trial medications requiring withdrawal from the study (as determined by the treating clinician).

\section{Outcome measures}

\section{Primary outcome}

The primary outcome is the proportion of children whose exacerbations have resolved by day 14. Exacerbations will be considered resolved when symptoms and signs are the same as the baseline state. Children who are withdrawn from the study or receive additional antibiotic treatment will be categorised as non-resolved.

\section{Secondary clinical outcomes}

The main secondary outcome is the PC-QOL score. Other outcomes are the time to next exacerbation; requirement for hospitalisation; duration of exacerbation (persistence of symptoms till 'return to baseline state') and $\mathrm{FEV}_{1} \%$ predicted.

\section{Secondary laboratory outcomes}

Serum markers (CRP, SAA, IL-6, IL-10, IP-10) and data on viruses and respiratory bacterial pathogens, including antibiotic susceptibility patterns to penicillin and azithromycin, will be the secondary laboratory outcomes.

\section{Sample size}

We plan to enrol 189 children (63 per arm), providing $84 \%$ power ( $\alpha=0.0245$, two-sided) to detect a halving of the number of children in the active arm achieving resolution by day 14 (that is, azithromycin or amoxicillinclavulanic acid: $60 \%$ resolved by day 14 , compared with placebo: $30 \%$ resolved). This is a conservative estimate when compared with our prospective data of persistent symptoms in $24 \%$ of children based on the same diary card [50]. As the primary outcome will be obtained in all enrolled children, a drop-out has not been factored in for the intention-to-treat analysis. With 20\% drop-out rate, data from 153 children (51 per arm) for 'per protocol' analysis provides a study power of $75 \%$. Both treatment arms are compared with the same placebo arm. While the maximum efficiency is attained by allocating more children to the placebo arm (that is, using an allocation ratio of $1: 1: \sqrt{ } 2$ ), we chose to use a $1: 1: 1$ allocation 
due to ethical concerns of deviating from standard care in respiratory centres.

In the main secondary outcome (PC-QOL), based on a between-group difference of 0.9 (minimum important difference [42]) (SD 0.9), our sample size provides power of $100 \%(\alpha=0.05)$ for data from at least 147 children (that is, assuming at least $80 \%$ retention of the 189 children enrolled). For secondary aim 2 (exploring factors that predict response to antibiotics), we will be examining eight main factors and thus a sample size of 147 exceeds the recommended minimum ( $\mathrm{n}=10$ per factor) [51]. The eight factors are smoking, age, underlying aetiology, detection of virus (any versus none, then single versus multiple viruses), presence of azithromycin resistance and blood markers (IL-6, IL-10, IP-10 levels).

\section{Statistical analysis and reporting}

Data will be reported and presented in accordance with the updated CONSORT criteria [52]. Children will be analysed according to allocation status (regardless of subsequent management). An interim analysis is planned and a data safety and monitoring committee will determine if the study should be ceased should superiority of any antibiotic be identified after $50 \%$ of sample size is achieved.

For our primary aim, the main effects of the interventions will be determined by comparing the primary outcome (resolution of exacerbation) between groups ((azithromycin versus placebo) and (amoxicillin-clavulanic acid versus placebo)). Children who exit the study as clinically worse or drop-outs prior to the end point will be considered non-resolved. Those who exit the study as 'returned to baseline' will be considered resolved. Odds ratios will be calculated and, if appropriate, number needed to treat (for benefit) will be expressed. Tests of a treatment arm versus placebo at the end of the study for the primary outcome will be performed at the $2.45 \%$ significance level to account for spending some alpha at the interim analysis. Per protocol analysis will be an $a$ priori secondary analysis.

\section{For secondary outcomes and aims}

For clinical secondary outcomes (secondary aim 1), t-tests or Mann-Whitney will be used for continuous variables (according to normality of data distribution). A KaplanMeier curve will be constructed for each group for 'time to resolution' and 'time to next exacerbation' as done previously [53]. For secondary aim 2 (factors that predict response to antibiotics), univariate analysis will be used to examine the biological factors listed above. Factors that have a $P$-value $<0.2$ will be included in a logistic regression model. Potential interactions (for example, virus with bacteria) will be examined in the model. Descriptive data will be used for secondary aim 3 (point prevalence of respiratory pathogens).

\section{Data safety monitoring committee}

A data safety monitoring committee has been established and has met prior to commencement of this study. It was determined that, when $50 \%$ of the sample size has been achieved, the stopping rules are as detailed below.

- If superiority between each antibiotic arm and the placebo arm is shown at significance level of 0.001, the study will cease. If superiority of only one antibiotic is shown, we will continue recruiting children to the other antibiotic arm and to the placebo arm but not to the superior antibiotic arm.

- If the serious adverse events (related to the medications) in each antibiotic arm outnumber the adverse events in the placebo arm at significance level of 0.01 or less, the study will cease. If increased adverse events of only one antibiotic is shown, we will continue recruiting children to the other antibiotic arm and to the placebo arm but not to the antibiotic arm related with increased adverse events. However, the study is not powered to detect between-group differences in total adverse events.

\section{Ethics approval}

The protocol has received ethical approval from the respective Human Research Ethics Committees of all the participating institutions (Darwin: Department of Health and Families and Menzies School of Health Research; Brisbane: Children's Health Services (Royal Children's Hospital) and University of Queensland; Perth: Princess Margaret Hospital; Melbourne: Royal Children's Hospital; Auckland: Northern Ethics Committee, Ministry of Health and Starship Children's Health local ethics committee). The study is being conducted under Australia's Therapeutic Goods Administration Clinical Trial Notification scheme.

\section{Discussion}

Despite the considerable global burden, bronchiectasis services receive disproportionately fewer allocated resources (clinical and research) when compared with other chronic respiratory diseases $[3,54,55]$. The marked paucity of RCTs $[21,55]$ is reflected in the existence of only a single (small) published placebo-controlled RCT in children with bronchiectasis $[21,56]$. That study described a reduction in sputum purulence and airway hyper-responsiveness in children receiving roxithromycin $(n=13)$ [57]. There are no RCTs on the management of bronchiectasis exacerbations in children [58]. Almost all current recommendations are based on CF management $[21,28]$. Such extrapolation can, on occasions, be detrimental for those with non-CF bronchiectasis. For example, a large RCT found that deoxyribonuclease (efficacious for CF) 
increased exacerbations and decline in $\mathrm{FEV}_{1}$ in adults with bronchiectasis [59] despite prior case reports advocating its use [60].

The importance of exacerbations in most chronic respiratory diseases is generally accepted. Unfortunately, data on triggers, definitions and effective treatment of bronchiectasis exacerbations in both children and adults are scarce [56,61,62]. Although viral triggers of acute exacerbations are well described in asthma [46] and COPD $[63,64]$, no such data exist for bronchiectasis. Whether other potential respiratory pathogens (M. pneumoniae and Chlamydia species) trigger exacerbations has never been examined. Our retrospective study found that $34 \%$ of exacerbations were preceded by a viral-like illness [29]. Thus, for the first time in this population, we will determine the nature and diversity of respiratory viruses $M$. pneumoniae and Chlamydia species associated with bronchiectasis exacerbations.

Our study addresses a large knowledge gap in an under-researched area [55]. If the intervention is successful, it would lead to improved short-term (and possibly long-term) health benefits. Conclusive results would produce changes to evidence-based standard treatment guidelines.

\section{The rationale for our chosen outcome measures and timeframe}

In our retrospective data of 115 respiratory exacerbations [29], we found that $35 \%$ of exacerbations failed to respond to oral antibiotic therapy (duration could not be determined) and required hospital admission. In our prospective cohort of 69 children followed for 900 childmonths (156 exacerbations), 36 exacerbations (23\%) were treated with intravenous antibiotics following persistence of symptoms, that is, non-resolution of the exacerbation episode. Generally, hospitalisation began three to five weeks following the initiation of oral antibiotics and 'return to baseline' occurred within two weeks of hospitalisation. Based on our data that $24 \%$ of otherwise well children in the community still have a cough associated with a viral infection at day 14 [50], we chose day 14 as the time point for this RCT. We also asked parents and clinicians about their willingness to use placebo for a period of time; 14 days was the limit with a safety exit point at day 7 .

Adult bronchiectasis studies show that QOL measures, particularly cough-specific QOL, are valid and important outcome measures $[62,65]$. Likewise, we have shown the utility of a paediatric chronic cough QOL (the PC-QOL) score in children with bronchiectasis [66].

In summary, our double-blind, double-dummy RCT that examines the superiority of azithromycin and amoxicillin-clavulanic acid (compared with placebo) for exacerbations of bronchiectasis in children has the potential to have both short-term gains and a long-term benefit for reducing the morbidity of bronchiectasis.

\section{Trial status}

We commenced recruitment in Darwin in mid-March 2012, Brisbane in June 2012 and the other sites are expected to commence in August 2012. We commenced randomisation in late May 2012.

\begin{abstract}
Abbreviations
BEST: Bronchiectasis Exacerbation Study; CF: cystic fibrosis; COPD: chronic obstructive pulmonary disease; CRP: C-reactive protein; ELISA: enzyme-linked immunosorbent assay; $\mathrm{FEV}_{1}$ : forced expiratory volume in one second; IL: interleukin; IP-10: interferon gamma-inducible protein 10; MIC: minimum inhibitory concentration; NS: nasal swab; PC-QOL: parent chronic cough quality of life; QOL: Quality of life; RCT: randomised controlled trial; SAA: serum amyloid A; SD: standard deviation.
\end{abstract}

\section{Competing interests}

The authors declare that they have no competing interests.

\section{Authors' contributions}

AC conceived the study, and participated in its design and coordination and drafted the manuscript. PM, CR, KG, PVA, AW, KO, PT and TS participated in its design and submission to the National Health and Medical Research Council. EB and GM participated in initiating the project and IMM in the viral analysis plan. IBM, CB and $\mathrm{HB}$ will assist in recruitment and assessment of the children. MDC advised on statistical issues. All authors read and approved the final manuscript.

\section{Authors' information}

$A B C, C F R, A C W, P P \vee A, C A B, I B M$ and $H M B$ are paediatric respiratory physicians, KG is a paediatric infectious disease physician, PJT is an adult respiratory physician, KFO is an epidemiologist, TPS and IMM are virologists, MDC is a statistician, EJB and GBM are research nurses and PM is a general paediatrician.

\section{Acknowledgements}

We thank the research staff (Lesley Versteegh, Clare Wilson, Sophie Anderson-James, Joanne Tuppin, Stacey Spencer, Carol Willis) for facilitating the study, Robert Ware for generating the randomisation sequences and Anita Champion for allocating the children and dispensing the medications. We are also grateful to members of the Indigenous Reference Group of the Child Health Division at Menzies for supporting this study and for overseeing the cultural aspects. We also thank Professor Alan Isles, Professor Craig Mellis and Associate Professor Chris Blyth for voluntarily providing their time in their participation as members of the data safety monitoring committee. The study is funded by a three-year National Health and Medical Research Council (NHMRC) project grant (number 1019834) and supported by a NHMRC Centre for Research Excellence in Lung Health of Aboriginal and Torres Strait Islander Children grant (number 1040830). AC (grant 545216) is supported by a NHMRC practitioner fellowship. KO is supported by Queensland Children's Medical Research Institute and Queensland Government Smart Futures fellowships. The views expressed in this publication are those of the authors and do not reflect the views of NHMRC.

\section{Author details}

${ }^{1}$ Child Health Division, Menzies School of Health Research, Charles Darwin University, Darwin, NT, Australia. ${ }^{2}$ Queensland Children's Respiratory Centre, Royal Children's Hospital, Brisbane, QLD, Australia. ${ }^{3}$ Queensland Children's Medical Research Institute, The University of Queensland, Brisbane, QLD, Australia. ${ }^{4}$ Queensland Paediatric Infectious Diseases Laboratory, Royal Children's Hospital, Brisbane, QLD, Australia. ${ }^{5}$ Department of Respiratory Medicine, Royal Children's Hospital, Murdoch Children's Research Institute, University of Melbourne, Melbourne, VIC, Australia. ${ }^{6}$ Department of Respiratory Medicine, Princess Margaret Hospital, Perth, Australia. ${ }^{7}$ Department of Respiratory Medicine, The Children's Hospital at Westmead \& Sydney Medical School, University of Sydney, Sydney, NSW, Australia. ${ }^{8}$ Royal Prince Alfred Hospital, Sydney, Australia. ${ }^{9}$ Department of Paediatrics, 
University of Auckland and Starship Children's Hospital, Auckland, New Zealand. ${ }^{10}$ Research and Education Support Division, Menzies School of Health Research, Charles Darwin University, Darwin, NT, Australia.

${ }^{11}$ Department of Paediatrics, Royal Darwin Hospital, Darwin, NT, Australia.

Received: 14 April 2012 Accepted: 16 August 2012

Published: 31 August 2012

\section{References}

1. Roberts HJ, Hubbard R: Trends in bronchiectasis mortality in England and Wales. Respir Med 2010, 104:981-985.

2. Seitz AE, Olivier KN, Steiner CA, De Oca RM, Holland SM, Prevots DR: Trends and burden of bronchiectasis-associated hospitalizations: USA, 19932006. Chest 2010, 138:944-949.

3. Santamaria F, Montella S, Pifferi M, Ragazzo V, De SS, De PN, Maglione M, Boner AL: A descriptive study of non-cystic fibrosis bronchiectasis in a pediatric population from central and southern Italy. Respiration 2009, 77:160-165.

4. Steinfort DP, Brady S, Weisinger HS, Einsiedel L: Bronchiectasis in Central Australia: a young face to an old disease. Respir Med 2008, 102:574-578.

5. Chang AB, Grimwood K, Macguire G, King PT, Morris PS, Torzillo PJ: Management of bronchiectasis and chronic suppurative lung disease (CSLD) in Indigenous children and adults from rural and remote Australian communities. Med J Aust 2008, 189:386-393.

6. Weycker D, Edelsberg J, Oster G, Tino G: Prevalence and economic burden of bronchiectasis. Clin Pulm Med 2005, 12:205-209.

7. Chang AB, Robertson CF, van Asperen PP, Glasgow NJ, Masters IB, Mellis CM, Landau LI, Teoh L, Morris PS: Can a management pathway for chronic cough in children improve clinical outcomes: protocol for a multicentre evaluation. Trials 2010, 11:103.

8. Chang AB, Robertson CF, van Asperen PP, Glasgow NJ, Mellis CM, Masters IB, Teoh L, Tjhung I, Morris PS, Petsky HL, Willis C, Landau LI: A multi-centre study on chronic cough in children: burden and etiologies based on a standardized management pathway. Chest 2012, Epub ahead of print.

9. O'Grady KA, Torzillo PJ, Chang AB: Hospitalisation of Indigenous children in the Northern Territory for lower respiratory illness in the first year of life. Med J Aust 2010, 192:586-590.

10. Chang AB, Masel JP, Boyce NC, Wheaton G, Torzillo PJ: Non-CF bronchiectasis-clinical and HRCT evaluation. Pediatr Pulmonol 2003, 35:477-483.

11. Singleton RJ, Morris A, Redding G, Poll J, Holck P, Martinez P, Kruse D, Bulkow LR, Petersen KM, Lewis C: Bronchiectasis in Alaska Native children: causes and clinical courses. Pediatr Pulmonol 2000, 29:182-187.

12. Donnelly DE, Critchlow A, Everard ML: Outcomes in children treated for persistent bacterial bronchitis. Thorax 2007, 62:80-84

13. Gupta S, Siddiqui S, Haldar P, Raj JV, Entwisle JJ, Wardlaw AJ, Bradding P, Pavord ID, Green RH, Brightling CE: Qualitative analysis of high resolution computed tomography scans in severe asthma. Chest 2009, 136:15211528.

14. Farrell PM: The prevalence of cystic fibrosis in the European Union. J Cyst Fibros 2008, 7:450-453.

15. O'Brien C, Guest PJ, Hill SL, Stockley RA: Physiological and radiological characterisation of patients diagnosed with chronic obstructive pulmonary disease in primary care. Thorax 2000, 55:635-642.

16. Dogru D, Nik-Ain A, Kiper N, Gocmen A, Ozcelik U, Yalcin E, Aslan AT: Bronchiectasis: the consequence of late diagnosis in chronic respiratory symptoms. J Trop Pediatr 2005, 51:362-365.

17. Haidopoulou K, Calder A, Jones A, Jaffe A, Sonnappa S: Bronchiectasis secondary to primary immunodeficiency in children: longitudinal changes in structure and function. Pediatr Pulmonol 2009, 44:669-675.

18. Bastardo CM, Sonnappa S, Stanojevic S, Navarro A, Lopez PM, Jaffe A, Bush A: Non-cystic fibrosis bronchiectasis in childhood: longitudinal growth and lung function. Thorax 2009, 64:246-251.

19. Ellerman A, Bisgaard $\mathrm{H}$ : Longitudinal study of lung function in a cohort of primary ciliary dyskinesia. Eur Respir J 1997, 10:2376-2379.

20. Kapur N, Masters IB, Chang AB: Longitudinal growth and lung function in pediatric non-CF bronchiectasis - what influences lung function stability? Chest 2010, 138:158-164.

21. Chang AB, Bell SC, Byrnes CA, Grimwood K, Holmes PW, King PT, Kolbe J, Landau LI, Maguire GP, McDonald MI, Reid DW, Thien FC, Torzillo PJ: Bronchiectasis and chronic suppurative lung disease (CSLD) in children and adults in Australian and New Zealand: Thoracic Society of Australia and New Zealand and Australian Lung Foundation Position Statement. Med J Aust 2010, 193:356-365.

22. King PT, Holdsworth SR, Farmer M, Freezer N, Villanueva E, Holmes PW: Phenotypes of adult bronchiectasis: onset of productive cough in childhood and adulthood. COPD 2009, 6:130-136.

23. Chang $A B$, Byrnes $C A$, Everard ML: Diagnosing and preventing chronic suppurative lung disease (CSLD) and bronchiectasis. Paediatr Respir Rev 2011, 12:97-103.

24. Martinez-Garcia MA, Soler-Cataluna JJ, Perpina-Tordera M, Roman-Sanchez $\mathrm{P}$, Soriano J: Factors associated with lung function decline in adult patients with stable non-cystic fibrosis bronchiectasis. Chest 2007, 132:1565-1572

25. Loebinger MR, Wells AU, Hansell DM, Chinyanganya N, Devaraj A, Meister M Wilson R: Mortality in bronchiectasis: a long-term study assessing the factors influencing survival. Eur Respir J 2009, 34:843-849.

26. Chang AB: Pediatric cough: children are not miniature adults. Lung 2010 188:S33-S40.

27. Chang $A B$, Redding GJ, Everard ML: State of the art - chronic wet cough: protracted bronchitis, chronic suppurative lung disease and bronchiectasis. Pediatr Pulmonol 2008, 43:519-531.

28. Pasteur MC, Bilton D, Hill AT: British Thoracic Society guideline for non-CF bronchiectasis. Thorax 2010, 65:i1-i58.

29. Kapur N, Masters IB, Chang AB: Exacerbations in non cystic fibrosis bronchiectasis: clinical features and investigations. Respir Med 2009, 103:1681-1687.

30. Cole PJ: Inflammation: a two edged sword. The model of bronchiectasis. Eur J Respir Dis 1986, 147:6-15.

31. Chang AB, Newman RG, Carlin J, Phelan PD, Robertson CF: Subjective scoring of cough in children: parent-completed vs child-completed diary cards vs an objective method. Eur Respir J 1998, 11:462-466

32. Chang AB, Eastburn MM, Gaffney J, Faoagali J, Cox NC, Masters IB: Cough quality in children: a comparison of subjective vs. bronchoscopic findings. Respir Res 2005, 6:3.

33. Kapur N, Masters IB, Morris PS, Galligan J, Ware R, Chang AB: Defining pulmonary exacerbation in children with non-cystic fibrosis bronchiectasis. Pediatr Pulmonol 2012, 47:68-75.

34. Leach AJ, Boswell JB, Asche V, Nienhuys TG, Mathews JD: Bacterial colonization of the nasopharynx predicts very early onset and persistence of otitis media in Australian aboriginal infants. Pediatr Infect Dis J 1994, 13:983-989.

35. Chang AB, Grimwood K, White AV, Maclennan C, Sloots TP, Sive A, McCallum GB, Mackay IM, Morris PS: Randomized placebo-controlled tria on azithromycin to reduce the morbidity of bronchiolitis in Indigenous Australian infants: rationale and protocol. Trials 2011, 12:94.

36. Hare KM, Grimwood K, Leach AJ, Smith-Vaughan HC, Torzillo PJ, Morris P, Chang $A B$ : Respiratory bacterial pathogens in the nasopharynx and lower airways of Australian Indigenous children with bronchiectasis. J Pediatr 2010, 157:1001-1005.

37. Wood LG, Scott HA, Garg ML, Gibson PG: Innate immune mechanisms linking non-esterified fatty acids and respiratory disease. Prog Lipid Res 2009, 48:27-43.

38. Martinez-Garcia MA, Perpina-Tordera M, Roman-Sanchez P, Soler-Cataluna Jj: Quality-of-life determinants in patients with clinically stable bronchiectasis. Chest 2005, 128:739-745.

39. Chang AB, Phelan PD, Robertson CF, Roberts RDG, Sawyer SM: Relationship between measurements of cough severity. Arch Dis Child 2003, 88:57-60.

40. Newcombe PA, Sheffield JK, Juniper EF, Halstead RA, Masters IB, Chang AB: Development of a parent-proxy quality-of-life chronic cough-specific questionnaire: clinical impact vs psychometric evaluations. Chest 2008 133:386-395.

41. Newcombe PA, Sheffield JK, Juniper EF, Petsky HL, Willis C, Chang AB: Validation of a parent-proxy quality-of-life questionnaire (PC-QOL) for paediatric chronic cough. Thorax 2010, 65:819-823.

42. Newcombe PA, Sheffield JK, Chang AB: Minimally important change in a parent-proxy quality of life questionnaire for pediatric chronic cough (PC-QOL). Chest 2010, 139:576-580.

43. Watt JP, O'Brien KL, Katz S, Bronsdon MA, Elliott J, Dallas J, Perilla MJ, Reid R, Murrow L, Facklam R, Santosham M, Whitney CG: Nasopharyngeal versus oropharyngeal sampling for detection of pneumococcal carriage in adults. J Clin Microbiol 2004, 42:4974-4976. 
44. Stubbs E, Hare K, Wilson C, Morris P, Leach AJ: Streptococcus pneumoniae and noncapsular Haemophilus influenzae nasal carriage and hand contamination in children: a comparison of two populations at risk of otitis media. Pediatr Infect Dis J 2005, 24:423-428.

45. Hare KM, Morris P, Smith-Vaughan H, Leach AJ: Random colony selection versus colony morphology for detection of multiple pneumococcal serotypes in nasopharyngeal swabs. Pediatr Infect Dis J 2008, 27:178-180.

46. Arden KE, Chang AB, Lambert SB, Nissen M, Sloots TP, Mackay IM: Newly identified respiratory viruses in children with asthma exacerbation not requiring admission into hospital. J Med Virology 2010, 82:1458-1461.

47. Syrmis MW, Whiley DM, Thomas M, Mackay IM, Williamson J, Siebert DJ, Nissen MD, Sloots TP: A sensitive, specific, and cost-effective multiplex reverse transcriptase-PCR assay for the detection of seven common respiratory viruses in respiratory samples. J Mol Diagn 2004, 6:125-131.

48. McErlean P, Shackelton LA, Andrews E, Webster DR, Lambert SB, Nissen MD, Sloots TP, Mackay IM: Distinguishing molecular features and clinical characteristics of a putative new rhinovirus species, human rhinovirus $\mathrm{C}$ (HRV C). PLoS One 2008, 3:e1847.

49. Ratcliff RM, Chang G, Kok T, Sloots TP: Molecular diagnosis of medical viruses. Curr Issues Mol Biol 2007, 9:87-102.

50. Petsky HL, Acworth JP, Clark R, Winter D, Masters IB, Chang AB: Asthma and protracted bronchitis: who fares better during an acute respiratory infection? J Paediatr Child Health 2009, 45:42-47.

51. Altman DG: Relation between several variables. In Practical Statistics for Medical Research. London: Chapman \& Hall; 1991:326-364.

52. Schulz KF, Altman DG, Moher D: CONSORT 2010 statement: updated guidelines for reporting parallel group randomised trials. Trials 2010, 11:32.

53. Chang AB, Torzillo PJ, Boyce NC, White AV, Stewart PA, Wheaton GR, Purdie DM, Wakerman J, Valery PC: Zinc and vitamin-A supplementation in Indigenous children hospitalised with episodes of lower respiratory tract infection: a randomised controlled trial. Med J Aust 2006, 184:107-112.

54. Kolbe J, Wells AU: Bronchiectasis: a neglected cause of respiratory morbidity and mortality. Respirology 1996, 1:221-225.

55. Tsang KW, Bilton D: Clinical challenges in managing bronchiectasis. Respirology 2009, 14:637-650.

56. Chang $A B$, Bilton $D$ : Non-cystic fibrosis bronchiectasis exacerbations. Thorax 2008, 63:269-276.

57. Koh YY, Lee MH, Sun YH, Sung KW, Chae JH: Effect of roxithromycin on airway responsiveness in children with bronchiectasis: a double-blind, placebo-controlled study. Eur Respir J 1997, 10:994-999.

58. Wurzel D, Marchant JM, Yerkovich ST, Upham JW, Masters IB, Chang AB: Short courses of antibiotics for children and adults with bronchiectasis. Cochrane Database Syst Rev 2011, 6:CD008695.

59. O'Donnell AE, Barker AF, llowite JS, Fick RB, rhDNase Study Group: Treatment of idiopathic bronchiectasis with aerosolized recombinant human DNase I. Chest 1998, 113:1329-1334.

60. Desai M, Weller PH, Spencer DA: Clinical benefit from nebulized human recombinant DNase in Kartagener's syndrome. Pediatr Pulmonol 1995, 20:307-308

61. Loebinger MR, Shoemark A, Berry M, Kemp M, Wilson R: Procalcitonin in stable and unstable patients with bronchiectasis. Chron Respir Dis 2008, 5:155-160.

62. Courtney JM, Kelly MG, Watt A, Garske L, Bradley J, Ennis M, Elborn JS: Quality of life and inflammation in exacerbations of bronchiectasis. Chron Respir Dis 2008, 5:161-168.

63. Proud D, Chow CW: Role of viral infections in asthma and chronic obstructive pulmonary disease. Am J Respir Cell Mol Biol 2006, 35:513-518.

64. Hutchinson AF, Black J, Thompson MA, Bozinovski S, Brand CA, Smallwood DM, Irving LB, Anderson GP: Identifying viral infections in vaccinated chronic obstructive pulmonary disease (COPD) patients using clinical features and inflammatory markers. Influenza Other Respi Viruses 2010, 4:33-39.

65. Murray MP, Turnbull K, Macquarrie S, Hill AT: Assessing response to treatment of exacerbations of bronchiectasis in adults. Eur Respir J 2009, 33:312-318.

66. Kapur N, Masters IB, Newcombe P, Chang AB: The burden of disease in pediatric non-cystic fibrosis bronchiectasis. Chest 2012, 141:1018-1024

\section{doi:10.1186/1745-6215-13-156}

Cite this article as: Chang et al:: Antibiotics for bronchiectasis exacerbations in children: rationale and study protocol for a randomised placebo-controlled trial. Trials 2012 13:156.

\section{Submit your next manuscript to BioMed Central and take full advantage of:}

- Convenient online submission

- Thorough peer review

- No space constraints or color figure charges

- Immediate publication on acceptance

- Inclusion in PubMed, CAS, Scopus and Google Scholar

- Research which is freely available for redistribution 